\title{
Adrenal hypoplasia congenita: Delayed presentation of a rare cause of primary adrenal insufficiency
}

\author{
*Jyoti Patodia ${ }^{1}$, Mukesh Kumar Gupta ${ }^{2}$ \\ Sri Lanka Journal of Child Health, 2018; 47(1): 77-79 \\ DOI: http://dx.doi.org/10.4038/sljch.v47i1.8436 \\ (Keywords: Adrenal insufficiency, congenital adrenal hypoplasia, hyperpigmentation, pre-adolescent)
}

\begin{abstract}
Introduction
Majority of cases of primary adrenal insufficiency are due to congenital adrenal hyperplasia $(\mathrm{CAH})$, adrenal hypoplasia congenita (AHC) being a rarer cause ${ }^{1}$. Here, we report a patient with AHC who presented in pre-adolescent phase with recurrent episodes of dehydration, shock and severe hyperpigmentation.
\end{abstract}

\section{Case Report}

A developmentally normal 11 year old boy was referred from a peripheral hospital where he was admitted for recurrent episodes of vomiting, dehydration, abdominal pain, malaise, anorexia, growth retardation and increasing pigmentation over body for past 3-4 years. He had severe dehydration with shock requiring inotropic support. There were two similar episodes in the past year requiring hospitalization. Patient had distinct craving for salty diet. He was asymptomatic in the neonatal period and early childhood. One younger male sibling had died at the age of one year due to some neurological disorder (developmental delay with seizures). He was investigated at the All India Institute of Medical Science, New Delhi but parents could not recall the diagnosis and records were not available. There are two elder sisters who are apparently normal. There was no history of abortion, consanguinity or any significant family history.

On examination, he was wasted and stunted with weight for age $(17.5 \mathrm{~kg})$ and height for age $(121 \mathrm{~cm})$ below $3 \mathrm{SD}$ as per World Health Organization

\footnotetext{
${ }^{1}$ Assistant Professor, ${ }^{2}$ Associate Professor, Mahatma Gandhi Medical College, India

*Correspondence:jyoti_ag7@hotmail.com

(Received on 06 October 2016: Accepted after revision on 18 November 2016)

The authors declare that there are no conflicts of interest

Personal funding was used for the project.

Open Access Article published under the Creative
}

Commons Attribution CC-BY (CC)
(WHO) standards. He had diffuse hyperpigmentation all over the body predominantly at mucosal surfaces Such as lips, gums and buccal mucosa. He had infantile gonads and sexual maturity rating (SMR) stage I. His vital functions and other systemic examination were normal.

Total white blood cell count, liver function tests and renal function tests were within normal limits. Serum sodium (122 meq/L) was low, serum potassium (6.1 $\mathrm{meq} / \mathrm{L})$ high and random blood glucose $(54 \mathrm{mg} / \mathrm{dl})$ low. Basal serum cortisol level $(0.208 \mu \mathrm{g} / \mathrm{dl})$ was low and the serum adrenocorticotropic hormone (ACTH) level $(1250 \mathrm{pg} / \mathrm{ml})$ high. ACTH stimulation test was done with an intravenous bolus $(125 \mu \mathrm{g})$ of ACTH (Synacthen) at 8 a.m. Both early morning cortisol at 8 am $(0.625 \mu \mathrm{g} / \mathrm{dl})$ and 60 minutes $(0.640 \mu \mathrm{g} / \mathrm{dl})$ after ACTH injection were low, suggestive of primary adrenal insufficiency. Serum levels of aldosterone, dehydroepiandrosterone sulphate (DHEAS) and 17hydroxyprogesterone (17-OHP) were within the normal range for age ruling out $\mathrm{CAH}$. Serum levels of follicle stimulating hormone (FSH) and luteinizing hormone $(\mathrm{LH})$ were in the pre-pubertal range and serum testosterone was very low viz. $36.1 \mathrm{ng} / \mathrm{dl}$ (normal range 241-827 ng/dl). X-ray chest and ultrasonogram of abdomen were normal. Abdominal magnetic resonance imaging (MRI) revealed a very small triangular left adrenal gland (4-5mm) and short and thin single limb of right adrenal gland $(1 \mathrm{~mm})$ suggestive of bilateral rudimentary adrenal glands. There was no obvious mass lesion, calcification or haemorrhage seen in bilateral adrenal glands. Serum lipid profile, serum creatine phosphokinase (CPK), human immunodeficiency virus (HIV), antinuclear antibody (ANA), MRI brain and karyotyping were normal.

Child was started on hydrocortisone $10-15 \mathrm{mg} / \mathrm{m}^{2}$ /day and fludrocortisone $0.1 \mathrm{mg} /$ day along with sodium supplementation (sodium chloride 1-2g/day) after which his electrolytes improved within a week and hyperpigmentation gradually disappeared. He did not have any further episodes of vomiting, dehydration or abdominal pain. His weight, height and general 
wellbeing had improved markedly at the 2 year follow up. However, SMR stage 1 remained the same.

\section{Discussion}

AHC was first described by Sikl $\mathrm{H}^{3}$. Clinical signs and symptoms of AHC include that of adrenal insufficiency e.g. weight loss, vomiting, dehydration, malaise, muscle weakness, hyperpigmentation and biochemical findings characteristics of glucocorticoid and mineralocorticoid deficiency: hyponatraemia, hyperkalaemia and hypoglycaemia ${ }^{4,5}$. The diagnosis of AHC, in our case was clinched by the typical clinical presentation with low serum cortisol, high serum ACTH, sub-optimal response on ACTH stimulation test, normal 17-OHP with rudimentary adrenal glands on MRI of adrenal glands.

Inheritance of AHC is commonly X-linked due to mutation or deletion of the DAX-1 gene and this form presents in early infancy ${ }^{2}$. In this form, hypogonadotropic hypogonadism and progressive high frequency deafness commonly occur in adolescence $^{6,7}$. The rarer autosomal recessive type of $\mathrm{AHC}$, which too is associated with hypogonadotropic hypogonadism, is due to a mutation or deletion of the gene encoding steroidogenic factor 1 on chromosome 9q33. Hypogonadotropic hypogonadism is clinically detected as pubertal delay and these patients may benefit from testosterone replacement ${ }^{5,6}$. Index patient presented in SMR stage I and there was no pubertal growth in 2 years of follow up. LH and FSH were also in the pre-pubertal range suggesting hypogonadotropic hypogonadism. However, we will have to wait till 15 years before labelling it as hypogonadism. In our case there was no hearing deficit at presentation and during 2 year follow up.

A small number of patients with AHC, usually the autosomal recessive form, may present between 2-9 years of age ${ }^{8}$, when acquired causes of adrenal failure such as autoimmune/infections should be ruled out, as in our case where ANA, HIV and total blood count were all normal. DAX-1 mutations also occur in glycerol kinase deficiency and Duchenne muscular dystrophy ${ }^{9,10}$ which were excluded, as serum creatinine kinase and triglyceride levels were normal.

Anatomically, in the X-linked type there is hypoplasia of the adrenal cortex with preservation of the fetal zone. In the autosomal recessive type there is absence of the fetal zone and severe hypoplasia of the definitive adult adrenal zone $e^{1,4,5}$. Rudimentary adrenal glands revealed on abdominal MRI, absence of hearing loss in the 2 year follow up and delayed presentation indicates autosomal recessive form of AHC, but death of a male sibling and healthy female siblings suggest $\mathrm{X}$ linked form. The mutations and deletions associated with AHC could not be detected, Karyotyping was normal and FISH analysis could not be done ${ }^{11}$.

The possibility of AHC should be considered in cases of adrenal insufficiency, not only in early infancy but also in the pre-adolescent age group as early recognition and treatment will improve the clinical outcome significantly. Long term monitoring of this patient is essential especially for hypogonadotropic hypogonadism and hearing deficits.

\section{References}

1. Kliegman RM, Stanton BF, Schor NF, Behrman RE. Adrenocortical insufficiency. Nelson Textbook of Pediatrics.19th edition. Philadelphia: Saunders/Elsevier; 2011.

2. Peter M, Viemann M, Partsch CJ, Sippell WG. Congenital adrenal hypoplasia: Clinical spectrum, experience with hormonal diagnosis and report on new point mutations of the DAX-1 gene. Journal of Clinical Endocrinology and Metabolism 1998; 83:2666-74.

https://doi.org/10.1210/jcem.83.8.5027 PMid: 9709929

3. Sikl H. Addison's disease due to congenital adrenal hypoplasia of the adrenals in an infant aged 33 days. Journal of Pathology and Bacteriology 1948; 60:323-6. https://doi.org/10.1002/path. 1700600220 PMid: 18099667

4. Ferraz-de-Souza B, Achermann JC. Disorders of adrenal development. Endocrine Development 2008; 13: 19-32. https://doi.org/10.1159/000134753 PMid: 18493131

5. Neary N, Nieman L. Adrenal insufficiency: aetiology, diagnosis and treatment. Current Opinion in Endocrinology, Diabetes and Obesity 2010; 17:217-23. https://doi.org/10.1097/MED.0b013e328338 f608

PMid: 20375886 PMCid: PMC2928659

6. Habiby RL, Boepple P, Nachtigall L, Sluss PM, Crowley WF, Jameson JL. Adrenal 
hypoplasia congenita with hypogonadotropic hypogonadism: evidence that DAX-1 mutations lead to combined hypothalamic and pituitary defects in gonadotropin production. Journal of Clinical Investigation 1996; 98(4):1055-62. https://doi.org/10.1172/JCI118866

PMid: 8770879 PMCid: PMC507522

7. Zachmann M, Fuchs E, Prader A. Progressive high frequency hearing loss: an additional feature in the syndrome of AHC and gonadotropin deficiency. European Journal of Paediatrics 1992; 151:167-9. https://doi.org/10.1007/BF01954375

8. Loke KY, Larry KS, Lee YS, Peter M, Drop SL. Pre-pubertal diagnosis of $\mathrm{x}$-linked congenital adrenal hypoplasia presenting after infancy. European Journal of Paediatrics 2000; 159: 671-5. https://doi.org/10.1007/PL00008404
9. Li N, Liu R, Zhang H, Yang J, Sun S, Zhang $\mathrm{M}$, et al. Seven novel DAX1 mutations with loss of function identified in Chinese patients with congenital adrenal hypoplasia. Journal of Clinical Endocrinology and Metabolism 2010; 95:104-11.

https://doi.org/10.1210/jc.2009-2408

PMid: 20573681

10. Francke U, Harper JF, Darras BT, et al. Congenital adrenal hypoplasia, myopathy, and glycerol kinase deficiency: molecular genetic evidence for deletions. American Journal of Human Genetics 1987; 40:21227.

PMid: 2883886 PMCid: PMC1684111

11. Guo W, Mason JS, Stone CG, et al. Diagnosis of X-linked adrenal hypoplasia congenita by mutation analysis of the DAX1 gene. Journal of the American Medical Association 1995; 274:324-30. https://doi.org/10.1001/jama.274.4.324 PMid: 7609262 